\title{
Autosomal Recessive Hypercholesterolemia
}

National Cancer Institute

\section{Source}

National Cancer Institute. Autosomal Recessive Hypercholesterolemia. NCI Thesaurus.

Code C128114.

An autosomal recessive condition caused by mutation(s) in the LDLRAP1 gene, encoding low density lipoprotein receptor adaptor protein 1. The phenotype is similar to that of familial hypercholesterolemia, but generally considered to be a milder form of hypercholesterolemia. 